\title{
Erratum to "Cripto Enhances Proliferation and Survival of Mesenchymal Stem Cells by Up-Regulating JAK2/STAT3 Pathway in a GRP78-Dependent Manner" [Biomol. Ther. 26 (2018) 464-473]
}

\author{
SeungPil Yun ${ }^{1}$, Chul Won Yun ${ }^{2}$, Jun Hee Lee ${ }^{3}$, SangMin Kim ${ }^{1}$ and Sang Hun Lee ${ }^{2, *}$ \\ ${ }^{1}$ Neuroregeneration and Stem Cell Programs, Institute for Cell Engineering, Department of Neurology, The Johns Hopkins University \\ School of Medicine, Baltimore, MD 21205, USA \\ ${ }^{2}$ Medical Science Research Institute, Soonchunhyang University, Seoul Hospital, Seoul 04401, Department of Medical Bioscience, \\ Soonchunhyang University, Asan 31151, Republic of Korea \\ ${ }^{3}$ Department of Pharmacology and Toxicology, University of Alabama at Birmingham School of Medicine, Birmingham, AL 35294, \\ USA
}

After publication of the paper "Cripto Enhances Proliferation and Survival of Mesenchymal Stem Cells by Up-Regulating JAK2/ STAT3 Pathway in a GRP78-Dependent Manner" by Yun et al. (2018), it was noticed that paper contains errors in Fig. 2C (p-STAT3 panel) and Fig. 4E. Because of unintentional errors made during the preparation of the Figs., the authors mistakenly used the unmatched image of western blot assay. The authors wish to replace the image of western blot assay in Fig. 2C (p-STAT3 panel) and Fig. 4E.

The corrected Fig. 2C (p-STAT3 panel) and Fig. 4E are published here to avoid confusion for readers. The conclusion of the article is unaffected by the error. The authors apologize for this inadvertent error and for any inconvenience caused.



Fig. 2. (C) MSCs were pretreated with a neutralizing antibody against GRP78 (100 ng/mL) for $24 \mathrm{~h}$ before the treatment with $100 \mathrm{ng} /$ $\mathrm{mL}$ Cripto for another $24 \mathrm{~h}$. Total protein was extracted and immunoblotted with antibodies against phosphorylated JAK2, phosphorylated STAT3, c-Myc, and cyclin D1. Amounts of $\beta$-actin were used as internal loading controls. Panel on the right illustrates mean normalized levels $( \pm$ SEM) of phosphorylated JAK2, phosphorylated STAT3, c-Myc, and cyclin D1 $(n=3)$. Statistical significance of differences is indicated as follows: ${ }^{*} p<0.05,{ }^{* *} p<0.01$ vs. control, ${ }^{\#} p<0.05,{ }^{\#} p<0.01$ vs. Cripto alone.

\section{Open Access https://doi.org/10.4062/biomolther.2021.452}

This is an Open Access article distributed under the terms of the Creative Commons Attribution Non-Commercial License (http://creativecommons.org/licenses/by-nc/4.0/) which permits unrestricted non-commercial use, distribution, and reproduction in any medium, provided the original work is properly cited.
DOI of original article : https://doi.org/10.4062/biomolther.2017.099

*Corresponding Author

E-mail: ykckss1114@nate.com

Tel: +82-2-709-9029, Fax: +82-2-792-5812 


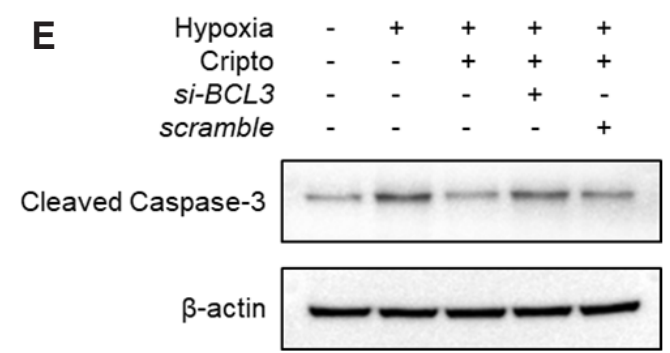

Fig. 4. (D, E) MSCs were transfected with BCL3 siRNA for $24 \mathrm{~h}$ followed by the treatment with $100 \mathrm{ng} / \mathrm{mL}$ Cripto for $24 \mathrm{~h}$, and then exposed to $200 \mu \mathrm{M} \mathrm{H}_{2} \mathrm{O}_{2}$ for $6 \mathrm{~h}$ or hypoxic condition for $96 \mathrm{~h}$. Total protein was extracted and immunoblotted with an antibody against caspase-3. Amounts of $\beta$-actin were used as internal loading controls. Lower panels in (D) and (E) indicate mean normalized levels ( \pm SEM) of caspase-3 $(\mathrm{n}=3)$. Statistical significance is indicated as follows: ${ }^{*} p<0.05$, ${ }^{* *} p<0.01$ vs. control, ${ }^{\sharp} p<0.05,{ }^{\#} p<0.01$ vs. $\mathrm{H}_{2} \mathrm{O}_{2}$ or hypoxia, ${ }^{\$} p<0.05,{ }^{\$ \$} p<0.01$ vs. Cripto under $\mathrm{H}_{2} \mathrm{O}_{2}$ or hypoxia, ${ }^{\&} p<0.05$, ${ }^{\text {\& }} p<0.01$ vs. Cripto with $\mathrm{BCL} 3$ siRNA under $\mathrm{H}_{2} \mathrm{O}_{2}$ or hypoxia.

\section{REFFERENCE}

Yun, S., Yun, C. W., Lee, J. H., Kim, S. and Lee, S. H. (2018) Cripto enhances proliferation and survival of mesenchymal stem cells by up-regulating JAK2/STAT3 pathway in a GRP78-dependent manner. Biomol. Ther. (Seoul) 26, 464-473. 